\title{
BRINGING IN SOCIETY, CULTURE AND POLITICS: VALUES AND ACCOUNTABILITY IN A BANGLADESHI NGO
}

\author{
David Lewis \\ (Chapter 7 in Forging Global Accountabilities: Participation, Pluralism, and Public Ethics \\ eds. Alnoor Ebrahim and Edward Weisband, Cambridge University Press, forthcoming 2007)
}

\section{Introduction}

Questions of accountability have become important and difficult ones in recent years for non-governmental organisations (NGOs) working in the development field. The rise of development NGOs during the late 1980s generated considerable expectations regarding their performance strengths and political contributions, but this was accompanied by growing doubts about their ability to maintain appropriate and effective levels of accountability to a wide range of 'stakeholders' including users, funders, staff and government (Edwards and Hulme, 1995). While this accountability critique was initially focused on the section of the NGO community rooted in industrialised countries - often known as 'Northern NGOs' - there is a growing recognition that a similar set of structural and relational accountability issues are also faced by NGOs with their roots in developing country contexts.

This chapter reflects on a recent study by the author of research and advocacy work undertaken by a large Bangladeshi NGO, referred to here by a pseudonym, Association for Credit and Empowerment (ACE). The study is considered in the light of issues of accountability and the chapter discusses the complex accountability problems which face even a relatively successful Southern NGO. ${ }^{1}$ The broader contribution of this chapter to the study of 'global accountabilities' lies in its exploration of the cultural embeddedness of accountability systems. To truly understand the effects of accountability on organizations, it is useful to examine them in context: within configurations of power and social institutions. Accountability may be a global phenomenon, promoted worldwide by donors in terms of managerial requirements and systems, but its manifestations, effects, and tensions play out locally.

Development NGOs are a highly diverse family of organisations and there has been considerable effort expended in the research literature on the different ways in which NGOs can be categorised and labelled. It would be both unnecessary and probably unproductive to attempt to summarise such wide-ranging debates here. A useful simple definition of such NGOs is that they are ' ... self-governing, private, not-for-profit organisations that are geared to improving the quality of life for disadvantaged people' (Vakil, 1997: p. 2060). However, the term NGO is in

\footnotetext{
${ }^{1}$ The anthropological convention of using a pseudonym has been maintained in this paper in order to conceal the formal identities of persons involved in the issues reported here. There are increasing political sensitivities apparent in the relations between some development NGOs and the government formed by the Bangladesh Nationalist Party (BNP) since the 2001 elections
} 
many ways an unhelpful one for analytical purposes. It includes a great many different types of organisations, from small local groups operating on a largely voluntary and informal basis, to large private development agencies with multi-million dollar budgets and many thousands of paid, professional staff. It may include some organisations which far from being relatively independent are in fact very close to the state or the private sector. There are other organisations which call themselves NGOs which have a 'bogus' character, simply finding the NGO label a convenient one to further their political or economic goals or as a means of claiming entitlements. In spite of such complexity, there is widespread agreement that there has been a rapid growth in the numbers and profile of NGOs in the past decade, both in the industrialised 'North', where NGOs are concerned with poverty and social justice at home and abroad, and in the aid-recipient countries of 'the South', where NGOs old and new have been identified as potential 'partners' by governments and international aid agencies (Salamon, 1994; Smillie, 1995). ${ }^{2}$

Alongside structural problems of accountability faced by NGOs in their relations with a wide range of stakeholders, there are also issues which need to be considered in relation to new thinking on the challenges of development work itself, and in relation to the overall context in which an NGO operates. For example, the need to link local and global agendas and constituencies within development work appears to be making accountability pressures for most NGOs grow increasingly more complex. As a result, there may be a 'trend towards more diverse and seemingly unconnected voices making requests or demands of the nonprofit organisation to be accountable for different things' (Fry, 1995: p. 191). At the same time, higher levels of diversity within and between NGOs brings new challenges in terms of integrating values and managing responsibilities between NGO staff, users and funders. In their study of South Asian NGOs, Smillie and Hailey (2001) identify 'the influence of context and culture' and 'balancing formality and informality' as key characteristics of successful NGOs. This chapter concludes that such problems are not simply managerial or technical ones as is frequently claimed, but instead will require analysis within a broader contextual framework for thinking about accountability which takes into account an organisation's position within wider fields of power and social networks.

This chapter focuses on a development NGO in Bangladesh which displays a complex set of accountability problems, both in relation to the operation of its formal organisational structures and systems, and as a consequence of the embeddedness of these systems in the wider society and institutions which surround the organisation. The NGO sector in Bangladesh has received considerable academic and donor attention in recent years, but there has been a stronger focus on formal accountability issues than on the nature of its embeddedness. Wider civil society in Bangladesh is strongly influenced by vertical patron-client relationships which characterise wider social structures which also help to structure relationships between people within and between organisations (Wood, 1997; Lewis, 2003). Within many development agencies, gender inequalities too are subtly reproduced, as in cases where wider attitudes inform the construction

\footnotetext{
${ }^{2}$ The rise of NGOs has been driven by a range of factors and these have been summarised elsewhere (Howell and Pearce, 2002; Lewis, 2002). During the past decade or so, NGOs have become established organisational actors within development policy and practice, but more critical questions are now being asked of their accountability and their performance (Edwards and Hulme 1995; Lewis and Wallace 2000).
} 
and labelling of 'gendered' programmes and activities. For example, it has been common in programmatic development discourse in Bangladesh to distinguish unhelpfully between men's 'employment' projects and women's 'income generating activities' (Kabeer, 2000).

\section{The Analysis of NGO Accountability}

Accountability is an issue which has been widely debated and theorised within the social sciences, well before the current period of heightened interest in accountability in relation to development NGOs. Within the wider tradition of thinking on accountability, it is possible to discern two central theoretical strands within the analysis of accountability. The first approach, following mainly from Weber's analysis of bureaucratic structures, has theorised accountability primarily in terms of rule-bound responses by organisations and individuals who must report to recognised authorities such as government agencies or donor organisations in order to ensure that the resources they receive are used properly and that the work they undertake is done effectively. The role of sanctions in order to maintain proper accountability is heavily emphasised in these types of accounts.

From an institutional perspective, accountability is often conceptualised as a 'principalagent' relationship in an agency such as a donor contracts with an NGO in order to provide a specified service (see Brown in this volume, and Brett, 1993). Such an arrangement requires that a set of checks and balances are put in place - such as mechanisms for reporting, monitoring and evaluation - which can ensure that an NGO provides these services in a trustworthy manner and that the service is provided properly in terms of cost-effectiveness, quality and targeting. This form of thinking also lies behind the 'audit culture' of much of the 'new managerialism' which has become a common feature of public life from the aid industry to higher education. O'Neill (2002) has reviewed the growth of what is often perceived to be a burdensome regime of inspection and target setting which, it is argued may have actually undermined levels of professionalism and trust within the health and education sectors in the UK. There has also been considerable concern around these themes within British academia, where the raise of audit culture has been analysed in neo-Foucauldian terms as part of a shift to neo-liberal forms of governance which depends in large part on the role of individual agency in which 'individuals, as active agents, are co-opted into regimes of power' (Shore and Wright, 2001: p. 760).

A second strand of thinking takes a more open-ended view characterised by a Durkheimian perspective of the integrative roles of organisations. This view of accountability takes as its starting point the idea that organisations are socially constructed entities. In this view, accountability can be understood as the maintenance of organisational integrity through dialogues among and between different stake-holders - such as staff, clients, governors, funders which seek to enhance effectiveness of an NGO. In this view, accountability processes form part of the ways in which organisations as socially constructed entities seek to construct shared systems of meanings and practices. Rather than seeing accountability issues as issues which are raised when things go wrong, accountability is instead viewed as a process which can be understood as part of the daily organisational life of an NGO (Fry, 1995). As well as emphasising the importance of issues such as organisational learning, this view also stresses the 
ethical dimension of organisational accountability: it is not simply as a set of controls to be imposed upon an organisation from the outside, but is a set of 'felt responsibilities' derived from within an organisation's values, mission and culture. This approach is also close to Biggs and Neame's (1995) thinking on NGO accountability which views the negotiations which follow from such felt responsibilities as unique opportunities for the more successful NGOs to learn and innovate.

As noted in the introductory chapter to this volume, most writers on NGO accountability draw attention to the fact that it takes on a complex, multidirectional character. For example, Najam (1996) demonstrates the ways in which an NGO is simultaneously accountable to its patrons such as donors, whose concerns are usually centred upon whether funds are used for designated purposes; to clients such as its users in the community, who are concerned with ensuring that the NGO acts in their interests, but have no clear means of ensuring this or the government, which may contract an NGO to carry out a particular task; and finally to itself, in the sense that each NGO has a vision which it seeks to actualise, and staff for whom it is responsible. Najam (1996: p. 351) argues that all too often NGOs "... tend to focus principally on their responsibility to their patrons, very often at the cost of their responsibility to their clients and to their own goals and vision".

The result is that for many NGOs accountability can become skewed and unbalanced. One result of this unbalanced accountability is the phenomenon of unplanned growth, where a 'successful' small-scale NGO evolves into a large, hierarchical organisation with many of the bureaucratic problems associated with traditional government agencies - such as a slowness to respond to problems, loss of contact with a certain part of the community, or the disappearance of a flexibility which made it possible to learn from experience. Another consequence is the problem of goal displacement, when for example an NGO drifts away from its original emphasis on education work towards credit delivery, due to the availability of donor funds for this purpose rather than from any special competence.

In the Bangladesh context, many development NGOs have drifted from quite radical roots in the transformational implications of aspects of Paolo Freire's conscientisation theory, for example, towards the credit and service delivery approach in part as a result of the greater availability of donor funds for such activities (Lewis, 1997). The rise of contracting arrangements between NGOs and bilateral and multilateral donors has fuelled concerns that wider NGO roles may be changing. For example, NGOs may be increasingly co-opted by states and donors into fulfilling the larger geo-political objectives of 'containing disorder' in parts of the post-Cold War world, rather than responding primarily to humanitarian needs and poverty (Fowler, 1995). Another important accountability problem has therefore traditionally concerned the unequal relationships which obtain within the 'aid industry' between donors, Northern NGOs and Southern NGOs. Many Northern NGOs have moved away from the direct implementation of projects in developing countries towards a 'partnership approach' with Southern NGOs, part of which includes efforts to undertake 'capacity building' work with local organisational partners in order to build greater levels of effectiveness and self-reliance, but the precise nature and terms of such partnerships often remain unclear (Lewis, 1998). 
Since accountability for NGOs can be understood as involves a combination of both internal and external factors (Ebrahim, 2003) it is clear that both of the above approaches to accountability will be relevant to both the analysis and practice of NGO accountability. It is also the case that accountability has important implications for the performance of NGOs, which has come under closer scrutiny in recent years. After the initial 'discovery' of NGOs as development actors in the 1980s, hard evidence of effective performance has proved elusive. Earlier assumptions made about the comparative advantages of NGOs over other kinds of organisation in poverty reduction work have been challenged. While there are many effective NGOs to be found, there are also many which lack basic management competencies and operate without a clear focus, or which exist for non-developmental reasons, such as building political patronage, or accumulating resources for leaders or staff. There are also questions about the management capacity of NGOs which may be motivated by ambitious objectives but which are in practice hindered by confused vision, weak administrative systems and domineering leadership. ${ }^{3}$

\section{Association for Credit and Empowerment}

Bangladesh's NGO sector has become an increasingly significant and well-documented feature of the country's social and economic life. It emerged primarily in the wake of the independence struggle in 1971, as part of the efforts of both local and international individuals and organisations to establish reconstruction and poverty reduction efforts within the new state (Lewis, 1997). Bangladesh's organisations are considerably varied in terms of their size and scope and some organisations such as the Grameen Bank have specialised in micro-finance service provision, while others such as the Bangladesh Rural Advancement Committee (BRAC) offer a wide range of different services - in addition to credit - in support of education, health and agriculture. Alongside service provision, there is increasing interest in advocacy work among some NGOs, and this case study focuses on an organisation which has been seeking for the past half decade or so to institutionalise its advocacy function within a special unit within the NGO.

The Association for Credit and Empowerment is one of the dozen or so large development NGOs which have now become well-established organisational actors on the Bangladesh development scene. ACE has been active since the mid-1970s and has steadily grown so that it now has field offices around much of the country. ACE's general approach has been to form a network of small groups of landless rural and urban poor across the country in order to build economic self-reliance through the provision of credit services and raising awareness for action on social justice issues. Unlike many NGOs in Bangladesh which have moved towards becoming micro-finance institutions and left behind earlier radical roots, ACE has tried hard to retain an 'activist' edge alongside its range of service delivery programmes. ACE's own accountability, at least in formal terms, is relatively clear: it is registered with the government, which must approve its receipt of foreign funds; it has established a donor consortium with which it agrees financial policy and systems; and it has begun the federation of its large network of grassroots groups which is designed to strengthen its accountability to users.

\footnotetext{
${ }^{3}$ For example, an evaluation of Danish NGOs in Bangladesh, Nicaragua and Tanzania presented findings that highlight a range of accountability problems (Oakley, 1999). In a comparison of four local NGOs in South Asia, Edwards (1999) suggests that the most effective development NGOs were characterised by independent thinking, clear goals, personal qualities of commitment among staff and volunteers and a close working relationship built up with clients over a long period of time.
} 
While ACE had effectively expanded its grassroots activities steadily, a point was reached in the early 1990s where its leaders began thinking in more ambitious terms. A new strategy was devised to help move it more fully into the policy influencing sphere and ACE's Centre for Advocacy and Research (CAR) was established in 1994. The main aim was to build a semi-autonomous institute which would conduct research on policy issues for advocacy, conduct media campaigning and undertake training with a wider range of 'civil society' organisations and issues in order to link more fully with social movements and citizen activism. CAR was therefore conceived as a response to a perceived need to balance micro-level interventions with efforts to challenge macro-level policy constraints on poverty reduction. CAR undertakes three main types of activities in its three units. Firstly, it develops advocacy campaigns on a range of issues such as land rights and the abuse of the banned chemical pesticides and lobbies for change. Secondly, CAR undertakes training work to build the capacity of the local and regional NGO sector to undertake advocacy work, basing the workshops in part of ACE's own experience. Thirdly, CAR undertakes research in support of its campaigning work. As well as commissioning research from local specialists, it has also established in 'in-house' research capacity with a team of young local researchers.

The establishment of CAR was an organisational response to a process of strategic reflection in the early 1990s on the implications of ACE's growth, learning and experience since it began its work back in the 1970s. At the heart of this discussion was a growing recognition of the importance of the need to improve organisational capacity in support of policy advocacy, training and research work. A new set of questions had emerged as a result of the NGO's growing development intervention experience and the changing political context in which ACE was operating. In particular, it was felt that ACE needed to build on its grassroots work in order to communicate its work and ideas more widely with policy makers and influence wider institutions and structures. What were the implications for ACE's work of the changing institutional landscape in Bangladesh, which shifted from a military dictatorship to a parliamentary democracy in 1991? How could ACE make use of the new democratic institutions which may offer potential opportunities for 'scaling up' through policy influence? Was it possible for ACE to counter 'in house' the poor availability of relevant, critical, high quality research and policy information accessible to development organisations?

Research into CAR's first five years of operation found significant achievements in the campaigning and advocacy fields, particularly as a pioneering effort in Bangladesh which had contributed to a new emphasis on NGO advocacy work during the 1990s in the NGO sector. ${ }^{4}$ At the same time, the study also highlighted a number of key organisational problems which were undermining CAR's performance, many of which have roots in accountability issues (Lewis and Madon, 2003). First was the finding that there were weaknesses in the ways in which advocacy and research agendas were being managed. A criticisms made of CAR's work was that, despite ACE's network of more than 100,000 grassroots groups across the country, much of the advocacy agenda was driven from the top - from opportunities identified by the senior Dhaka-

\footnotetext{
${ }^{4}$ Research within CAR was undertaken by the author as part of a review organised by ACE as an outcome of the mid-term evaluation carried out by its four-donor funding consortium. Fieldwork was carried out during two 14 days trips to Bangladesh in early 2001, and included semi-structured interviews with a range of internal and external CAR stakeholders (staff, group members, government, wider civil society).
} 
based leadership and the Director of the organisation in particular. While it was seen as important to try to influence policy through maintaining good personal contacts with powerful key figures in the government 'at the centre', it was pointed out by some informants that opportunities to build a more participatory approach were being missed. Some field staff and group members also felt that what CAR was doing had little direct relevance to the day to day struggles of ordinary people. Other activists and NGOs pointed out that the great potential strength of ACE as an organisation - as opposed to small urban policy think-tanks which undertake campaigning work - was to root its campaigning more directly to the needs and concerns of its beneficiaries. This was not just an issue of effectiveness but also of accountability, since ACE as an organisation is committed to responding to the needs of the poorest in society and assisting them with their efforts to organise and act.

The second area of weakness concerned organisational learning, which was restricted by the absence of an effective information system with which to judge the impact of CAR's advocacy work (Lewis and Madon, 2003). What tended to happen was that campaigns or training workshops were undertaken and considered to have either met with 'success' - such as a change in the implementation of the law - or with 'failure' - no perceivable impact - and then were gradually replaced with new activities as other events, concerns or opportunities presented themselves. This pragmatic approach was certainly flexible and responsive, but CAR lacked the tools with which to draw conclusions from these experiences and distil lessons which could be used to improve its programmes. The fact that there was considerable activity evident overall was taken as proof that CAR was operating effectively.

During the review process, more detailed discussions helped to build a framework through which the impact of advocacy work could be assessed according to a clear set of criteria. Four types of impact were identified: (i) the immediate outcomes in terms of the aim of the campaign; (ii) whether the process of policy making has changed over the longer term or whether the result was a mere 'one off'; (iii) the results in terms of ACE's own learning about approaches to future advocacy work; and (iv) whether wider relationships for future action amongst civil society actors has been strengthened, regardless of whether the campaign had been a success in terms of meeting its goals.

The importance of viewing organisational systems - and therefore accountability processes - as social systems can be usefully elaborated in relation to the complexity of CAR's structures, systems and people. One of the striking findings to emerge from the review was the contrast between formal and informal advocacy work undertaken. ${ }^{5}$ CAR has developed an internal advocacy team, which is designed to develop and undertake advocacy work on behalf of the organisations, but the reality tends to be that the senior ACE leadership play the major role in campaigning. The leadership have moved into a prominent position on the Dhaka 'civil society scene' and have constructed wider relationships with politicians and bureaucrats. There is a strong 'personal' dimension to successful policy advocacy work, seen as necessary for success by some senior staff, and power is heavily concentrated at the top of the organisation among the

\footnotetext{
${ }^{5}$ Smillie and Hailey's recent (2001) book on South Asian NGOs bears out this duality between the formal and the informal as a key component of management practice within many large South Asian NGOs.
} 
senior leadership. ${ }^{6}$ Balancing this tension between individualised advocacy by senior staff, and grassroots driven advocacy carried out and supported by teams at different levels of the organisation proved a major problem. It was not unusual to find grassroots ACE groups in the more remote areas of the country who were rather dismissive of work done at the centre in the name of advocacy work because could appear remote and self-serving. But from the leadership point of view, it is felt that effective political action in Bangladesh requires mobilising both personalised networks of horizontal trust and the building of vertical patron-client linkages. It is perhaps not surprising that ACE and its leaders have embarked on both strategies.

At the same time, CAR has faced a major problem in attracting and keeping high quality research and advocacy staff at junior and middle levels. A succession of well qualified young researchers - many educated outside the country in British or United States universities, had joined CAR with high expectations only to leave a year or even a few months later. Partly this was a result of being tempted away by the promise of higher salaries within an increasingly competitive development agency job market, but it was also partly because they felt undervalued within CAR's overall organisational hierarchy and culture. ${ }^{7}$ This problem helps reveals the tensions which exist between formal and informal views of human resource management. There is an ideology within ACE, propagated by its founders, that solidaristic values among staff should take precedent over financial reward, at least in the early years of involvement with the organisation. ${ }^{8}$ While pay and conditions were kept a little lower than those found in the increasingly competitive development agency sector, which is dominated by foreign organisations such as the UN and international NGOs. CAR's terms and conditions were found to be unattractive to many young foreign-educated Bangladeshi researchers faced with more lucrative opportunities in other areas of the development industry.

However, the ACE leadership were reluctant to pay higher salaries to CAR which could cause resentment among other sections of the staff, particularly those in remote field posts. The leadership complained that their organisation was a 'family' whose shared values were being challenged by a more commercially-minded younger generation who were on one occasion referred to in a derogatory way as 'mercenaries'. Tensions between 'activists' and 'professionals' were also seen by the leadership as a cause of these problems - between those staff committed to the values and aims of the organisation who were prepared to work for low salaries and those who saw NGO work as a career and needed a decent salary and a clear opportunity for progression in the job. The gulf between the need to reform the formal system to

\footnotetext{
${ }^{6}$ This fits well with recent approaches to the study of NGOs which takes an 'actor-oriented approach' to organisations which acknowledges that organisational boundaries are highly artificial and personal kinship ties and informal networks may be just as influential in determining organisational behaviour as formal systems, labels and structures (Hilhorst, 2003).

${ }^{7}$ A detailed conceptual review of the importance of organisational culture in development agencies is provided in Lewis et al (2003).

${ }^{8}$ The key founders were mainly student activists who, within a pre-professionalised period of organisation building, saw development NGOs as a vehicle for social work back up by a strong level of ideological commitment to working with the poor. This has evolved into a powerful founding myth - essentially rooted in truth, but occasionally somewhat romanticised - which deployed from time to time by senior managers in their discussions with disaffected junior staff. There are now quite determined efforts being made to hold on to this idea and ensure its reproduction within the organisational culture of ACE. However, as an ideology it has less appeal to the newer young generation of employees faced with an increasingly difficult and competitive job market.
} 
suit younger, specialised, in-demand recruits and the prevailing social vision - voiced through the social symbol of 'the organisational family' - of the older generation of founder leaders seemed likely to prolong the problem. An organisational 'culture conflict', with its roots in both internal politics and external changes, is severely weakening organisational performance

Culture and context therefore have a significant bearing on accountability issues within ACE. Furthermore, the political environment in which NGOs in Bangladesh operate is hazardous, leading many NGOs to take on a somewhat defensive organisational form which can impede the operation of information systems. Tensions between government and NGOs are commonplace as NGOs increasingly move into roles previously occupied by the public sector. At the same time, the political nature of campaigning work challenges the position of entrenched elites, such as rural landowners. Some of ACE's staff and members have been attacked and even killed as a result of conflicts over land. There are also occasional tensions and conflicts with religious groups who take exception to the ideology of gender equality which NGOs such as ACE seek to put into practice in their programmes. Many NGOs which engage in work with women have also been criticised by conservative elements from the within the religious community, some of whom view education and empowerment programmes for women as an undesirable challenge to local values and customs. Finally, relations with foreign donors who fund substantial areas of the work of the NGOs can also prove problematic. While the donors themselves make strong accountability demands of the NGOs they fund, there are frequent accusations from sections of the public that NGOs' legitimacy and political integrity is compromised by the fact that they are accountable through funding relationships to powerful organisations and interests outside the country.

All these pressures contribute to a 'culture of defensiveness' which can be observed in NGOs where there can be a reluctance, for example, to commission research which might prove challenging to the organisational status quo and values. Added to these pressures are the prevailing patterns of patron-client relationships and social hierarchy, which within NGOs which tend to internalise and reproduce significant social inequality and vertical relationships which then require high levels of deference in the management of relationships between senior and junior staff (Wood, 1997). One of the most serious results of this is a 'culture of defensiveness', which includes a reluctance to confront less successful activities and initiatives, which has the result of reducing organisational learning. From the top managers downwards, the organisation is placed under constant pressure by this prevailing culture to demonstrate success but ignore failure, through sustaining an agenda of action and the addition of new activities, but there is little incentive given to find time to reflect and learn.

Growing linkages between local, national and global levels of action are apparent from the CAR experience. While advocacy work has been undertaken with some success at the local and national levels, there is a growing awareness of the need to understand the global context of policy formulation and implementation as well as the importance of linking local priorities more effectively with wider action. Such thinking informs CAR's regional advocacy training work, and last year the first regional training workshop was held with participants from all over South Asia from a range of NGOs. CAR was also part of the recent initiative, which set up an NGO working group to examine the World Bank's activities in Bangladesh, and another focusing on the consequences and implications of its structural adjustment policies. However, it was found 
in the review that national advocacy work tended to take an 'elite' form - based on the personal values, interests and contacts of senior staff - and often remained somewhat unconnected from the priorities of ACE's grassroots groups themselves. For example, we have seen that there were weaknesses in the ways information was being managed from the grassroots level for seeking explanations as to why particular campaigns 'succeeded' or 'failed', thus impairing levels of organisational learning. This then led to a growing perception amongst field staff that the functioning of CAR had little relevance for day-to-day struggles of ordinary people. As CAR engages more fully with complex global advocacy, a wider set of specialised knowledge and skills will be needed to maintain close ties with events 'on the ground' and a key priority for the NGO continues to be the effort to connect local, national and international efforts more coherently.

As a result of the CAR review, there has been a recognition among ACE leadership and staff more widely that attention now needs to be given to strengthening the organisational values and systems which support research and advocacy. This recognition goes well beyond technical systems towards a clearer recognition that problems related to staff skills, culture, politics are crucial to the improvement of accountability and performance. There is now a plan to reconvene CAR's international advisory board as soon as possible - which has been more or less inactive for the past two years - in order to turn the review findings into new strategies. Within a few months of completion of the review, ACE took a decision to increase its investment in the capacity of young research staff and five were sent on appropriate overseas masters programmes later that year in order to begin the strengthening process for the future. This has in part diffused the tensions which were contributing to low morale among many of the CAR staff. However, the election on the Bangladesh Nationalist Party (BNP) government shortly after the review took place has created a more difficult political environment for ACE, since it is one of a group of NGOs which are considered by the government to have identified themselves with the previous government.

\section{Conclusion}

The case study presented in this chapter suggests that NGO accountability can be only partly understood through analysing the formal bureaucratic operation of organisational relationships and the internal systems established for activities such as advocacy, monitoring and evaluation. While these foci are important - and at times can be seen to be quite problematic - for analysing a development NGO, they can provide only a partial understanding of accountability processes. To understand the organisational realities of an NGO we must go further and deeper into local social realities, evoked in Hilhorst's (2003) recent book on the 'real world' of NGOs. NGO structures, activities and relationships are socially embedded within institutions and power structures at both local and international levels. While accountability is increasingly a global phenomenon - with expectations for bureaucratic operation, management, auditing, and performance assessment - its impacts differ across more localized or regionalized social structure.

A number of problems described in the case study lend themselves to analysis along these lines. First, CAR's advocacy work was characterised by a strong personal dimension in the ways in which advocacy themes were identified and addressed 'from the top', in many cases with 
relatively little discussion with grassroots users, in a style which corresponds with prevailing cultures of personalised leadership and management. The second is the importance of both formal and informal dimensions of human resource management, where culture conflict emerges as an outcome of both power asymmetries between managers - involving at least a degree of degree of patron-clientelism in the ways that these operate - and the socially constructed nature of existing accountability systems. The third is the idea of a 'culture of defensiveness' which is derived in part from the nature of these power relations and the difficult political environment in which NGOs operate, and in part as an outcome of the extreme vulnerability felt, at least by more junior managerial staff, in relation to the wider economic climate and job market in Bangladesh.

There are some accountability problems which can be addressed by building clearer communication linkages between different levels of the organisation, such as creating opportunities for greater staff and group voice in the shaping of CAR's advocacy and research agendas, or linking advocacy more clearly to evaluation learning. But there are other organisational problems that are rooted in wider context of society, culture and politics. For example, it is constantly necessary to negotiate an appropriate relationship with government which can serve to reassure citizens that ACE is a legitimate and responsible organisation, but which avoids negative interference based on political involvement an NGO's internal affairs on party political lines. While some of the problems identified during the ACE review have generated internal discussions about trying to find solutions, there is a danger is that certain 'inward looking' responses - such as the attempt to build a stronger culture of loyalty and solidarity within the organisation to try to reduce rising levels of staff turnover - may not be able to address wider contextual realities in the form of increasing economic and social pressures affecting a new, younger generation of NGO staff.

It is the first of the two approaches to accountability discussed above which has taken hold most strongly both in policy circles and in public perceptions. The 'audit culture' model of accountability which follows from current climates of managerialism may ultimately weaken organisations because, by creating an erosion of trust through the creation of perverse incentives, it may lead NGO staff and leaders to make arbitrary or unprofessional choices. At the same time, formal thinking on accountability does not sit well with the cultural embeddedness of organisational systems within a development NGO. O'Neill's (2002) argument for a form of trust-based 'intelligent accountability', which pays more attention to the perceptions and realities of users than to endlessly detailed and complex validation documents and targets, is of potential value to development NGOs. She writes:

Those who are called to account should give an account of what they have done and of their successes and failures to others who have sufficient time and experience to assess the evidence and report on it.

Such a view fits with the need to adjust thinking on NGO accountability to take far more account of its socially-constructed aspects. While the formal structural view of accountability is still an important one, it threatens to overbalance thinking away from accountability systems which can take better account of the complexity of development work, the political realities in which NGOs operate and the cultural relationships which both constrain and structure action. 



\section{References}

Ebrahim, A. (2003). "Accountability in practice: mechanisms for NGOs". World Development $31(5), 813-829$.

Edwards, M. and Hulme, D. (eds). (1992). Making A Difference: NGOs and Development in a Changing World. London: Earthscan Publications.

Edwards, M. (1999). "NGO performance - what breeds success?" World Development, 27(2): 361-374.

Edwards, M. and Hulme, D. (eds). (1995). Beyond the Magic Bullet: NGO Performance and Accountability in the Post-Cold War World. London: Macmillan.

Etzioni, A. (Spring 1972). "The Untapped Potential of the 'Third Sector'”. Business and Society Review, 1, 39-44.

Fowler, A. (1997). Striking A Balance: A Guide to Enhancing the Effectiveness of NGOs in International Development. London: Earthscan.

Fry, R. (1995). Accountability in organizational life: problem or opportunity. Nonprofit Management and Leadership.

Hilhorst, D. (2003). The Real World of NGOs: Discourse, Diversity and Development. London: Zed Books.

Howell, J. and J. Pearce. (2001). Civil society and development: a critical exploration. Coulder, CO: Lynne Rienner.

Hulme, D. and M. Edwards (eds). (1997). Too Close for Comfort? NGOs, States and Donors. London: Macmillan.

Kabeer, N. (2000). The Power To Choose: Bangladeshi Women and Labour Market Decisions in London and Dhaka. London: Verso.

Lewis, D. (2004). “On the Difficulty of Studying 'Civil Society': Reflections on NGOs, State and Democracy in Bangladesh". Contributions to Indian Sociology.

Lewis, D. (2002). "Organisation and Management in the Third Sector: Towards A CrossCultural Research Agenda”. Nonprofit Management and Leadership, 13(1), 67-83.

Lewis, D. (1998). "Development NGOs and the challenge of partnership: changing relations between North and South". Social Policy and Administration, 32(5), 501-512.

Lewis, D. and Wallace, T. (eds). (2000). New Roles and Relevance: Development NGOs and the Challenge of Change. Hartford: Kumarian Press. 
Lewis, D. and S. Madon. (2003). "Information systems and non-governmental organisations (NGOs): advocacy, organisational learning and accountability in a Southern NGO". The Information Society, 20(2).

Lewis, D. A.Bebbington, S.Batterbury, A. Shah, E.Olson, M.S. Siddiqi and S.Duvall. (2003). "Practice, power and meaning: frameworks for studying organizational culture in multi-agency rural development projects". Journal of International Development, 15, 1-17.

Najam, A. (1996). "NGO accountability: a conceptual framework". Development Policy Review, 14, 339-353.

O’Neill, O. (2002). “A Question of Trust”. Lecture 4, BBC Reith Lectures. http://www.bbc.co.uk/radio4/reith2002/.

Salamon, L. (1994). Partners in Public Service: Government-Nonprofit Relations in the Modern Welfare State. Baltimore: Johns Hopkins.

Shore, C. and S. Wright. (2001). "Reply to Maguire". Journal of the Royal Anthropological Institute 7,4 (December) pp759-763.

Smillie, I. (1995) The Alms Bazaar: Altruism Under Fire - Non-Profit Organisations and International Development. London: Intermediate Technology Publications.

Smillie, I. And Hailey, J. (2001) Managing for Change: Leadership, Strategy and Management. London: Earthscan.

Vakil, A. (1997). "Confronting the classification problem: towards a taxonomy of NGOs". World Development, 25(12), 2057-2071.

Wood, G.D. (1997) "States without citizens: the problem of the franchise state". Chapter 5 in NGOs, States and Donors ed. D. Hulme and M. Edwards. London: Macmillan. 